\title{
Chemical and Ceramic Methods for the Safe Storage of Actinides
}

\author{
Oak Ridge National Laboratory
}

September 1997

\section{Progress Report}

\section{Principal Investigator}

L. A. Boatner

(423) 574-5492 (Phone)

(423) 574-4814 (Fax)

lb4@ornl.gov

Oak Ridge National Laboratory

P.0. Box 2008, MS-6056

Oak Ridge, Tennessee 37831

\section{Co-Investigator}

Peter E. D. Morgan

(805) 373-4545 (Phone)

(805) 373-4775 (Fax)

pemorgan@ @rsc.rockwell.com

Rockwell International Science Center

P.O. Box 1085

Thousand Oaks, California 91360

\section{Contributors}

A. Meldrum, ORNL

Bryan Chakoumakos, ORNL

Joanne O. Ramey, ORNL 


\section{Research Objective}

Oak Ridge National Laboratory (ORNL) and the Rockwell Science Center of Thousand Oaks, California, are carrying out a joint investigation of the chemical, physical, thermal, and radiation-resistance properties of the lanthanide orthophosphates (monazites) in both ceramic and single-crystal form with the objective of developing the scientific and technical base required for the application of these materials to the storage or disposal of actinide elements, including plutonium. An additional major objective of the research effort is to investigate the technical and scientific problems associated with the formation of both phase-pure monazite ceramics and multiphase monazite-ceramic composites for waste disposal or waste storage applications. These latter investigations encompass the development of low-temperature chemical synthesis routes for the formation of monoclinic monazite phases and the study of the densification properties of lanthanide orthophosphate powders to produce stable, high-density ceramics.

\section{Research Statement}

This research effort addresses several basic issues associated with the characteristics of lanthanide orthophosphates that make this class of materials extremely attractive candidates for application to the storage of actinide elements in general and plutonium in particular. Additionally, these materials are potentially important refractory ceramics in their own right, and many of the scientific issues addressed in this project are applicable to the development of what will constitute a new, highly stable family of ceramics for applications in a number of energyrelated areas. The areas that are being investigated in this effort include the following.

- Sintering mechanisms involved in the formation of high-density monazite ceramics. The fundamental structural properties of grain boundaries in monazite ceramics will be investigated using high-resolution transmission electron microscopy and the powerful Zcontrast scanning transmission electron microscopy technique developed at ORNL. The proposed studies will examine the full densification process beginning with the mechanisms involved in initial-stage sintering and then proceeding to the subsequent stages of gram growth and development, grain boundary motion and diffusion, and void elimination.

- The development of the effects of texturing in the microstructure of monazite ceramics during sintering. Texturing effects have recently been observed in the microstructure of tetragonal-symmetry lanthanide orthophosphate ceramics using a new technique developed at ORNL that uses paramagnetic ions as structural probes. The implications of preferred microstructural orientation on various chemical and physical properties of lanthanide orthophosphate ceramics, as well as other types of ceramic materials, are not well understood at this time. The ORNL-developed electron paramagnetic resonnance texture-analysis method 'will be used to characterize monazite ceramics in terms of preferential crystallographic orientations. This information will subsequently be correlated with other characterization data regarding the overall ceramic microstructural features created during the sintering process.

- Fundamental investigations of monazite ceramics and their physical and chemical characteristics carried out using single crystals. Relatively large single crystals of both the 
monoclinic (monazite) and tetragonal (zircon) structural forms of the lanthanide orthophosphates are grown at ORNL in both pure and doped forms. Monazite single crystals grown at ORNL will be used to form specific gram boundaries with controlled relative orientations between two grams. The structural properties of these boundaries will then be investigated in detail on an atomic scale at ORNL though the application of scanning transmission electron microscopy (STEM) and transmission electron microscopy (TEM) techniques.

Chemical stability and leaching studies of monazites. The methods of Rutherford backscattering spectroscopy (RBS) and ion channeling, coupled with the implantation of heavy-ion markers such as bismuth, previously used at ORNL in the study of the dissolution kinetics of borosilicate glasses, will be applied to investigations of the chemical stability of monazites in aqueous environments. The dissolution kinetics of Bi-implanted borosilicate glasses in water were readily determined quantitatively in prior work by means of this technique. This technique is also a very powerful tool for the study of the diffusion of impurity ions in the lanthanide orthophosphates. RBS methods will be applied to determinations of the diffusion kinetics of various impurity ions in monazites. The bulkdiffusion properties of impurities will be determined using ORNL-grown crystals implanted with marker ions; Grain-boundary diffusion rates will be determined by using sintered polycrystalline monazite ceramics. The determination of the diffusion rates of impurities in monazite ceramics is central to establishing, at a high confidence level, that these materials will remain closed systems over long periods of time and under deleterious environmental conditions.

Investigations of sintering aids for the densification of monazite ceramics. The goal of these studies will be to determine the properties of sintering additives so that monazites may be densified at the lowest possible temperature that will result in a high density in the final sintered body. By using RBS depth-profiling techniques, the motion of implanted markers can be followed as a function of sintering temperature, and these results, in turn, will be correlated with STEM investigations of the location of impurities that diffuse to the grain boundaries of the material.

Studies of displacive radiation damage in monazites. Much of the previously available information regarding the radiation damage behavior of monazites is based on observations of natural minerals, and therefore, the sample history for these specimens was not established. Interpreting the results under these circumstances is clearly associated with a significant degree of uncertainty. The study of heavy-particle radiation damage and recovery in monoclinic monazites is being carried out in a collaboration involving L. A. Boatner at ORNL, Alkaviathes Meldrum (presently at ORNL and formerly at the University of New Mexico), and R. C. Ewing at the University of Michigan. These investigations encompass studies of the effects of the ion-bombardment temperature, annealing temperature, and atmosphere and of the nature of the implanted ionicspecies on the radiation damage properties of monazites. 


\section{Research Progress}

Funding for the ORNL portion of this effort only became available in late July of FY 1997, and accordingly, there has only been a very limited time period available in which to initiate the planned program of research. Nevertheless, a considerable amount of progress has been made, particularly in the area of the study of radiation damage and recovery effects in the monazites. This has been possible by means of a collaborative effort between ORNL and R. C. Ewing of the University of Michigan and his former graduate student, who is currently an ORNL postdoctoral appointee. By means of this collaboration, it was possible to carry out a number of investigations that are pertinent to the present research effort, at no cost to ORNL, while at the same time providing a research topic and collaborative guidance to a $\mathrm{Ph}$.D. candidate who has subsequently received his degree. The progress made through this approach is summarized below along with other progress relevant to the investigation of the formation and characterization of monazite ceramics.

\section{Radiation Damage and Recovery in Monazites}

The monazite structure orthophosphates $\left(\mathrm{LaPO}_{4}, \mathrm{PrPO}_{4}, \mathrm{NdPO}_{4}, \mathrm{SmPO}_{4}, \mathrm{EuPO}_{4}, \mathrm{GdPO}_{4}\right.$, and natural monazite) plus the zircon structure analogs $\left(\mathrm{ScPO}_{4}, \mathrm{YPO}_{4}, \mathrm{TmPO}_{4}, \mathrm{TmPO}_{4}, \mathrm{YbPO}_{4}\right.$, and $\mathrm{LuPO}_{4}$ ) were irradiated by $800 \mathrm{keV} \mathrm{Kr}$ ions in the temperature range of 20 to $600 \mathrm{~K}$. The critical amorphization dose for these materials was determined in situ as a function of temperature by means of selected-area electron diffraction. This work led to the significant finding that the monazite structure orthophosphates have lower critical temperatures for amorphization than their zircon structure analogues and are in general more difficult to amorphize at temperatures above about $300 \mathrm{~K}$.

Related work has shown that phosphates and silicates with the same type crystal structure exhibit large differences in their response to radiation. Specifically, the phosphates have lower critical temperatures of amorphization and are, therefore, more difficult to amorphize. The effect of chemical impurities appears to enhance the resistance to recrystallization of amorphized phosphates and the ratio of the electronic-to-nuclear stopping power of the materials correlates well with the critical amorphization temperature and correctly predicts the ease of amorphization within each structure type (i.e., the monazite or zircon structure).

\section{Ceramic Properties Investigations}

Fine-grained powders of $\mathrm{LaPO}_{4}$ have been prepared by means of the technique of precipitation from molten urea. These powders have been examined by X-ray diffraction and were found to be phase pure and to have particle sizes that are sufficiently large for use in the planned series of experiments that will be carried out to determine the anisotropic thermal expansion properties of the monoclinic monazite structure up to $1400^{\circ} \mathrm{C}$. These experiments will be carried out using neutron diffraction techniques, and they will use the capabilities of the High Flux Isotope Reactor (HFIR) reactor at ORNL. The diffraction data will be refined at each temperature in order to accurately determine the lattice parameters $\mathbf{a}, \mathbf{b}, \mathbf{c}$ and beta for the monazite structure. These results will have important implications for the application of monazites to the formation of multiphase ceramic waste forms and to the application of the lanthanide orthophosphates to ceramic science in general. 


\section{Summary of Accomplishments}

- In-depth investigations of radiation damage and recovery effects in monazites were carried out by means of in situ TEM investigations performed as a function of temperature.

- Samples were prepared and characterized for studies of the anisotropic thermal expansion of monazite over a wide temperature range extending up to $1400^{\circ} \mathrm{C}$. Experiments are under way using neutron diffraction methods at HFIR at ORNL.

\section{Papers and Abstracts}

Meldrum, A., L. A. Boatner, and R. C. Ewing. "Displacive Radiation Effects in the Monazite and Zircon Structure Orthophosphates." Submitted to physics Review. In press.

Meldrum, A., L. A. Boatner, and R. C. Ewing. 1997. "Electron-Irradiation-Induced Nucleation and Growth in Amorphous $\mathrm{LaPO}_{4}$ and $\mathrm{ScPO}_{4}$." J. Mater. Res. 12: 1816.

Meldrum, A., L. A. Boatner, and R. C. Ewing. "Electron-Irradiation-Induced Crystallization of Amorphous Orthophosphates." In Microstructure Evolution During Irradiation, edited by T. Diaz de la Rubia, G. S. Was, I. M. Robertson, and L. W. Hobbs, eds., Material Research Society Symposium Proceedings, Materials Research Society, Pittsburgh, Penn., 1997. In press.

Meldrum, A., L. A. Boatner, and R. C. Ewing. "Ion-Beam Amorphization of Monazite and Zircon: Implications for U-Pb Geochronology." Submitted to Geochimica et Cosmochimica Acta. In press.

Meldrum, A., L. A. Boatner, L. M. Wang, and R. C. Ewing. "Ion-Beam-Induced Amorphization of $\mathrm{LaPO}_{4}$ and $\mathrm{ScPO}_{4}$." Submitted to Nuclear Instruments Methods Physics Research B. In press.

Meldrum, A., R. C. Ewing, and L. A. Boatner. 1997. "Effects of Displacive and Ionizing Radiation on Several Perovskite-Structure Compounds." Presented at "Radiation Effects in Insulators-9 (REI-9)," Knoxville, Tenn., September 14-19, 1997.

Nipko, J. C., C. K. Loong, M. Loewenhaupt, M. Braden, W. Reichart, and L. A. Boatner, "Lattice Dynamics of Xenotime: The Phonon Dispersion Relations and Density of States of $\mathrm{LuPO}_{4}$." Submitted to Physics Review. In press. 